\title{
Mãe, mestra e guia: uma análise da iconografia de Santa'Anna
}

\section{Maria Beatriz de Mello e Souza}

A gegunda santa mais cultuada no Brasil colônia é Anna, mãe da Virtra-Reforma - sempre acompanha Sant'Anna nos três tipos iconográficos aqui estudados: Santas Mães, Sant'Anna Guia e, sobretudo, Sant'Anna Mestra.

As igrejas da América portuguesa passaram a receber esculturas de Sant'Anna com grande freqüência a partir do século XVII. Em Minas Gerais — um dos mais importantes centros artísticos da colônia - a imagem esculpida de Sant'Anna é comum em paróquias, capelas e oratórios domésticos. Esta capitania abriga um número expressivo de locais de culto dedicados à mãe da Virgem Maria, onde ela é representada sobre o altar-mor.

As informações sobre a criação das imagens provêm mais de suas características físicas do que de fontes escritas. Anônimas e sem data, estas imagens podem ter sido levadas para Minas Gerais ou podem ter sido criadas, nesta capitania, por artistas cujo perfil social desconhecemos. Em termos estilísticos e cronológicos, os espaldares das cadeiras de Sant'Anna indicam que as obras podem pertencer ao período do reinado de dom João V (1706-1750) ou de dom José I (1750-1777).

O grau de sofisticação varia tanto quanto ao material quanto às dimensões das esculturas. A madeira é o material mais usado para a talha e, em particular, para as obras com formas mais perfeitas. Há também imagens feitas em terracota e pedra. Além da policromia, algumas esculturas em madeira revelam o emprego de técnicas elaboradas no tratamento da superfície da pele (como a encarnação) e das vestes (o douramento e o estofamento). As obras esculpidas em grande formato podem ter sido destinadas para os retábulos de altares em paróquias e capelas. As imagens de dimensões menores deveriam ser para a devoção doméstica, podendo ser guardadas em oratórios.

Topoi, Rio de Janeiro, dezembro 2002, pp. 232-250. 
Dois aspectos físicos indicam o papel da imagem como objeto de culto. O primeiro concerne aos olhos de vidro presentes nas esculturas mais sofisticadas. A verossimilhança do olhar da figura de devoção era um aspecto essencial para que a escultura pudesse comover o fiel, de acordo com as diretrizes da Contra-Reforma. Ademais, os orifícios nas cabeças esculpidas revelam que Anna e Maria eram adornadas com coroas e resplendores típicos da cultura barroca ibero-americana. Podiam ser feitos em metais preciosos e doados como ex-votos. $\mathrm{O}$ afeto que permeava a comunicação pelo olhar e o adorno revela a razão de ser da escultura: aproximar o fiel de Sant'Anna.

O objetivo deste estudo é compreender a iconografia da imagem à luz desta sua função cultural: ser um objeto de devoção. A história das idéias elucida as metáforas atribuídas a Anna, centradas nos papéis de mãe educadora e esposa santa. A primeira parte do texto trata da iconografia das Santas Mães (figura 1) e a segunda da devoção a Sant'Anna nas Minas Gerais. A terceira parte analisa a iconografia de Sant'Anna Guia e Sant'Anna Mestra (figura 2). Em Minas, Anna foi representada sobretudo como Mestra cujo atributo essencial é o livro.

\section{Sant'Anna, Mãe de Maria}

O culto da Virgem Maria tornou-se importante no Ocidente a partir do século XII, com a valorização da genealogia e da infância de Cristo. Anteriormente, o Cristianismo era centrado nas figuras de Cristo adulto e de santos. Maria tornou-se uma figura de destaque, em particular na Europa católica e na América Latina. A mariologia passou a desenvolver os temas da vida da Virgem.

O primeiro episódio da vida de Maria foi sua concepção no ventre de sua mãe, Sant'Anna. Uma festa conhecida como a "Concepção de Anna" era celebrada em Constantinopla desde meados do século VIII e no Ocidente um século mais tarde. ${ }^{1}$ A devoção a Sant'Anna era estreitamente vinculada a este papel de concepção da Virgem.

Anna e seu esposo Joaquim são figuras ausentes das Escrituras canônicas. Seus nomes são documentados pela primeira vez em um evangelho apócrifo composto no século II. O Evangelho de Tiago, ou evange- 
lho da infância da Virgem e de Cristo, é o que mais fala da concepção de Maria. ${ }^{2}$ Ele conta como Anna e Joaquim viram suas ofertas recusadas no Templo por causa da esterilidade do casal, considerada uma maldição no judaísmo. Após a separação do casal e muitas orações, o anjo exorta-os a se encontrarem na Porta Dourada de Jerusalém onde Maria seria concebida pelo abraço dos dois. O Evangelho de Tiago foi muito difundido no Ocidente em livros hagiográficos, na liturgia e na iconografia.

O tema da vida de Maria inspirou a primeira manifestação conhecida da devoção a Sant'Anna no Brasil. Trata-se do primeiro poema escrito na América portuguesa, obra-prima de José de Anchieta (Tenerife, 1534 Espírito Santo, 1597). Foi composto em 1563, ano da conclusão do Concílio de Trento, que tentava frear o culto de Sant'Anna. A obra começa com a concepção de Maria. Graças à pureza de sua filha, Anna deu à luz sem dores. ${ }^{3} \mathrm{O}$ jesuíta exalta todas as funções maternais que Anna assumiu, mesmo as mais comuns, como a amamentação. Os papéis mais importantes de Sant'Anna foram a concepção de Maria, sua educação e sua preparação ao voto de virgindade, ao ser consagrada no Templo. $\mathrm{O}$ valor do poema, além da propagação pioneira de certas idéias teológicas no Brasil, é o de traduzi-las em um modelo de comportamento para os fiéis, onde as virtudes da virgindade e da castidade ganham relevo. Embora o maior religioso da colônia pregasse a contemplação e a imitação da "imagem" de Maria, seu manuscrito em latim dificilmente poderia ser divulgado entre os leigos. As artes visuais iriam se encarregar da criação de imagens que fossem eloqüentes em sociedades majoritariamente analfabetas, como as da América portuguesa.

\section{Sant'Anna, a raiz}

"Que a raiz seja Santa Anna, Maria Santíssima a vara, e Christo Bem nosso a flor". João Evangelista, $1739^{4}$

A história da iconografia de Sant'Anna segue os passos da história das idéias religiosas e do culto. No Ocidente, a partir do século XII, a iconografia de Anna torna-se mais complexa, podendo abarcar formas alegóricas e narrativas. Os principais temas representados são os papéis de Anna e 
Joaquim como progenitores na genealogia messiânica, mesmo quando a figura de Maria está ausente. Estes papéis já eram predestinados no pensamento de Deus, como indica o tema iconográfico Anna [e Joaquim] contempla [m] em êxtase a imagem de sua filha já santificada por Deus antes de ser concebida, do qual conhecemos raras variantes dos séculos XVI e XVII no mundo luso-brasileiro.

Os artistas podiam representar os pais de Maria para evocar a sua concepção. Trata-se de uma alegoria, quer dizer, de uma representação que evoca uma realidade outra ${ }^{5}$. Alguns temas alegóricos eram baseados no Evangelho de Tiago, como o encontro de Anna e Joaquim na Porta Dourada de Jerusalem. A Contra-Reforma veio a desvalorizar este tema na arte; Inocêncio XI chegou a bani-lo em 1677.

Outros temas alegóricos evocam a genealogia messiânica de forma a privilegiar os avós de Cristo. O tipo iconográfico mais alegórico da figura de Anna encontra-se em variantes da Árvore de Jessé (inspirado em Isaías 11:1-2). Ele representa uma árvore que sai do tórax ou da orelha de Jessé com figuras em número variável. Na sua origem, no século XII, este tipo iconográfico era cristológico. Às vezes, os profetas da Encarnação eram representados dos dois lados da árvore. Sobre os galhos há reis que foram ancestrais de Cristo. No alto da árvore se situa a Virgem, e no galho superior seu Filho. Em algumas variações posteriores, o tipo iconográfico tornou-se mariológico Ressaltava-se a genealogia da Virgem mais do que a de seu Filho, que era excluído. Neste caso, os pais de Maria ganham destaque: há árvores compostas apenas com Anna e Joaquim. Apesar de restringida pela Contra-Reforma, a iconografia da Árvore de Jesséainda inspirou obras em Portugal. No Brasil, no entanto, ela é muito rara. ${ }^{6}$

\section{As Santas Mães}

O quam pulcra est casta generatio cum claritate.

(“Festo S. Annae Matris”, 1760) ${ }^{7}$

Como a "gloriosa matriarca" era mais valorizada do que o "glorioso patriarca" - termos encontrados nos textos da Contra-Reforma para invo- 
car Anna e Joaquim - a imagem de Maria com sua mãe tornou-se mais comum do que aquela com o casal. O tipo iconográfico mais explícito sobre a maternidade é Anna grávida: Maria menina envolta em raios de luz era desenhada sobre o ventre de Sant'Anna. Consideradas indecentes, as imagens de Anna grávida não foram favorecidas pela Igreja na Contra-Reforma.

A maternidade de Anna é inserida em um contexto genealógico quando ela é representada com Maria adulta e o Menino Jesus. Este tipo iconográfico é conhecido como Santas Mães no mundo luso-brasileiro (SantAnna Triplice na Espanha e Anna selbdritt em alemão). As esculturas das Santas Mães foram difundidas na Europa do norte e na Península Ibérica na Baixa Idade Média. Neste período, Anna é representada em pé ou sentada: a avó do Messias segura em seus braços Maria, que, por sua vez, segura o Menino. $\mathrm{Na}$ arte da Contra-Reforma é mais comum encontrá-la sentada ao lado de sua filha. Em muitas obras, é representado um livro que pode ser segurado por Anna ou pelas duas mães ao mesmo tempo (figura 1). O Menino pode estar no colo da Virgem ou entre as duas Santas Mães.

Às vezes a figura da mãe de Anna, Emerencianna (ou Esmeria), era acrescentada às Santas Mães, segurando os três outros personagens em seus braços ou, simplesmente, acompanhando-os. Quatro gerações eram então representadas: três mães, adultas, e o Deus Menino. As imagens com Emerencianna eram particularmente difundidas nas igrejas carmelitas, pois acreditava-se que a bisavó de Cristo teria entrado na Ordem do Carmo. Fora deste contexto, estas imagens são muito raras no período da Contra-Reforma.

Entre os diversos tipos iconográficos vigentes na Baixa Idade Média, a Contra-Reforma veio a selecionar três para exaltar a mãe de Maria. Estes tipos herdaram dois temas fundamentais da arte medieval: o papel de Sant'Anna na genealogia messiânica (presente no tipo das Santas Mães) e, sobretudo, a relação entre Anna e sua filha enquanto criança (explícita nos tipos de Sant'Anna Mestra e Sant'Anna Guia, estudados na terceira parte deste texto). Para compreender a seletividade desta mentalidade religiosa, é preciso elucidar o paroxismo a que chegaram os defensores e os críticos da devoção a Sant'Anna no século XVI, e o papel que lhe foi atribuído entre as "Santas Mães" que foram ancestrais de Cristo.

O culto de Sant'Anna se desenvolveu intensamente e sem obstáculos do século XII ao XVI. Sant'Anna tornou-se, a partir do século XV, um argu- 
mento em favor da doutrina da Imaculada Conceição de Maria: a pureza da mãe confirmava a ausência de pecado na concepção da filha. ${ }^{8}$ Defensores desta doutrina, como os franciscanos e posteriormente os jesuítas, propagaram fervorosamente o culto a Sant'Anna.

No entanto, no século XVI este culto foi criticado tanto por protestantes quanto por católicos, às vezes pelas mesmas razóes. Um dos pretextos para restringir o culto era a condenação de sua fonte, o Evangelho de Tiago, considerado apócrifo. A causa profunda da oposição já se manifestava no pensamento de São Bernardo de Claraval (†1153): o perigo da doutrina da Imaculada Conceição era provocar a "santificação matriarcal" das ancestrais de Cristo. De fato, papas vieram a condenar a atribuição de privilégios de Maria à sua mãe: a virgindade e a ausência de pecado. Intensificou-se a devoção a Emerencianna e a outros personagens acrescentados nas histórias sobre a santa parentela. ${ }^{9}$ A iconografia da santa parentela que ganhou corpo após ser revelada a Colette Boilet $(\dagger 1447)$, reformadora das Clarissas - teve vida curta após o Concílio de Trento e suas novas diretrizes para a arte sacra.

A maioria dos historiadores percebeu o fenômeno da "santificação matriarcal" apenas como um abuso popular em torno de lendas religiosas. É preciso atentar, contudo, para um vínculo importante. É o que une historicamente a valorização da linhagem feminina e o aspecto "matrifocal" de certas sociedades como as de Minas Gerais, onde o culto a Sant'Anna era preeminente. ${ }^{10} \mathrm{~A}$ arte barroca indica que a oposição quinhentista ao culto à mãe de Maria não conseguiu interrompê-lo. Uma das razões era o papel atribuído à segunda santa mais importante da colônia: ser padroeira dos mineradores.

\section{Sant'Anna, protetora das Minas Gerais e de seus desbravadores}

Sant'Anna "he a mysteriosa Arca, que teve em si a Maria

Santissima, urna de ouro". Frei Francisco da Madre de Deus, $1798^{11}$

Os eclesiásticos foram os primeiros propagadores da devoção à mãe de Maria na América portuguesa. No século XVIIII, seus gestos e suas idéias 
indicam que esta devoção se intensifica. Por exemplo, em 1759, a pedido do bispo Antonio do Desterro, Clemente XIII proclama Sant'Anna padroeira do Rio de Janeiro. Em 1782, Pio VI declara Sant'Anna "padroeira e protetora” de São Paulo. As publicações setecentistas do clero brasileiro e português testemunham a vitalidade da devoção a Sant'Anna. Havia livros que abordavam sua vida e seus milagres, ${ }^{12}$ outros de natureza mística, ${ }^{13}$ bem como modelos para sua novena. ${ }^{14}$

Em Portugal e no Brasil, Sant'Anna foi objeto de vários sermões, um gênero literário enriquecedor para a cultura barroca e essencial para os propósitos da Contra-Reforma. Um tema de destaque na parenética era o papel de Sant'Anna como “o tesouro escondido no campo" da parábola sobre o reino dos céus (Mateus 13). Esta parábola deve ter sido particularmente eloqüente em Minas, pois ela evoca o homem que, tendo achado o tesouro, vende tudo que possui para comprar o campo onde ele se encontra. Havia também uma analogia entre Anna e o campo que contem o tesouro. "A pureza é um tesouro escondido": ${ }^{15}$ quando Sant'Anna oferece Maria ao Templo, o voto de virgindade da filha representa o tesouro escondido da mãe. Em 1646, este gesto é imitado pelos pais da noviça Anna Maria, quando deixam seu tesouro para tornar-se Clarissa no Mosteiro de Sant'Anna no dia da festa da padroeira. O dote da religiosa é composto de seus três votos: a obediência é uma "pérola" (Sant'Anna é comparada ao mar) e a castidade é "o tesouro do Evangelho".

A exegese bíblica e o imaginário vieram reforçar a mesma idéia e darlhe uma tradução na prática. Sant'Anna tornou-se padroeira de mineradores — tradição já corrente na Espanha - e de "moedeiros". Assim como as minas, Anna escondia ouro em seu ventre: Maria Imaculada. A analogia teve ressonância no mundo rural das Minas Gerais, alvo das esperanças que colonizadores nutriam há séculos. No âmbito urbano, os moedeiros realizavam festas anuais em homenagem a Sant'Anna. O sermão pregado na festa dos moedeiros na catedral de Salvador — bem como aquele pregado três anos antes na Sé de Lisboa - é fundado na analogia entre Anna e o tesouro do evangelho. ${ }^{16}$

Vejamos dois exemplos de leigos que também associavam Anna ao tesouro bíblico. Em 1770, o governador de São Paulo — capitania que 
muito contribuiu para o povoamento de Minas — exprimiu sua gratidão pela descoberta de ouro a Sant'Anna, homenageando-lhe em grandes festas. É notável o testemunho documentado por uma escrava que se prostituía em Minas, Rosa Maria Egipcíaca da Vera Cruz (1719 — após 1765). Ao converter-se, Rosa tornou-se devota de Sant'Anna e sua família e criou um rosário no qual — assim como no rosário mariano — quinze mistérios da vida de Sant'Anna eram meditados. Em um deles, a mãe de Maria “era cofre em que o Altíssimo depositou o tesouro da pureza suma, sem mistura nem macula, a Virgem Intacta”. ${ }^{17}$ A experiência religiosa desta alforriada era composta de conhecimentos teológicos sofisticados, idéias populares, manifestações de afeto e visões típicas da cultura barroca. ${ }^{18}$

Em Minas Gerais, capelas foram consagradas a Sant'Anna desde o início do povoamento. No culto como na iconografia, a "gloriosa matriarca" ocupava uma posição de destaque em relação a seu esposo. Por exemplo, entre os 52 padroeiros de irmandades, Anna foi a sétima; havia uma única irmandade dedicada a Joaquim. ${ }^{19}$ Entre os 33 padroeiros de 74 paróquias, Anna foi a terceira mais importante.

O "glorioso patriarca" Joaquim era, em geral, associado a sua esposa. Ainda no século XVIII, insistiu-se para que Joaquim fosse apresentado como o único esposo de Anna, contrariamente à lenda difundida nos séculos XV e XVI segundo a qual ela teria tido três maridos. ${ }^{20}$ Tratava-se de uma precaução prudente para que Anna e Joaquim pudessem se tornar um modelo para doutrinar uma sociedade onde a bigamia era freqüente. ${ }^{21}$ Evocar laços familiares de Sant'Anna além daqueles com Maria e Joaquim era razão para ser denunciado ao Santo Ofício da Inquisição. ${ }^{22}$

Assim, compreende-se por que a esposa de Joaquim é invocada como "protetora das viúvas" em uma litania anotada por Rosa Egipcíaca. A ladainha invoca suas virtudes e seu papel em relação aos homens da sagrada família:

"Sant'Anna, espelho de obediência, ora pro nobis!

Sant'Anna, espelho de paciência, ora pro nobis!

Sant'Anna, proteção das viúvas, ora pro nobis!

Sant'Anna, mulher forte, ora pro nobis!

Sant'Anna, avó de Cristo, ora pro nobis! 
Sant'Anna, sogra de São José, ora pro nobis !

Sant'Anna, da prole dos patriarcas, ora pro nobis!"23

Em Minas Gerais, os devotos de Sant'Anna apresentavam um perfil social bem diversificado. Havia religiosos e leigos, homens e mulheres, livres e escravos. Assim como na Península Ibérica, entre os milagres que lhe foram atribuídos destacam-se os relacionados à saúde dos fiéis, um papel também atribuído à Virgem. Os ex-votos pintados por escravos dão testemunho do papel de cura atribuído a Sant'Anna.

Em Minas, a popularidade da devoção a Sant'Anna e a sua família é testemunhada nos registros de batismo e ordenação bem como nos testamentos. No século XVIII, religiosos e leigos adotavam com freqüência os nomes compostos destas figuras de devoção. A identificação com estes santos através do nome levava os fiéis a invocar a sua proteção até a morte.

A devoção dos homens mineradores e do clero ocupava um espaço público. Ao analisarmos as representações artísticas de Sant'Anna, estaremos deixando o universo da mineração e das atividades eclesiásticas para penetrar em um universo do privado, tipicamente feminino. Por um lado, estaremos diante de imagens feitas sobretudo para a devoção doméstica. Por outro lado, estas imagens representam, justamente, o que ocorria na intimidade dos lares: a mãe exercendo o papel de mestra e guia.

\section{Sant'Anna, Mestra e Guia}

Sant'Anna é a "ingular Mestra da perfeição evangélica". João Alvares Soares, Salvador, $1733^{24}$

$\mathrm{Na}$ arte barroca, a iconografia de Sant'Anna evoca mais a educação de Maria do que sua concepção e genealogia. Dois tipos iconográficos ressaltam este tema: Sant'Anna Mestra e Sant'Anna Guia. Aqui Maria é sempre menina, mesmo quando representada como uma mulher em miniatura. Ela já tem idade para aprender questôes religiosas e morais.

O tipo iconográfico de Sant'Anna Mestra foi criado no século XIII ou antes, possivelmente na Inglaterra. ${ }^{25} \mathrm{O}$ livro que Anna carrega é seu atributo essencial, como indicam, por exemplo, os "medalhões" sobre os 
retábulos de seus altares. Em Minas, Sant’Anna Mestra é representada sempre com o livro aberto nas mãos ou sobre os joelhos. Se estiver em pé, a filha está nos seus braços. Se Anna estiver sentada — sua posição mais habitual —, Maria está no seu colo ou em pé ao seu lado (fig.3). Sua cadeira lembra o tipo iconográfico mariano Sedes Sapientiae, no qual a Virgem é identificada com o trono da Sabedoria, segurando seu Filho ao colo.

O tipo de Sant'Anna Mestra pode apresentar variaçóes em pinturas e esculturas, como a presença de seu esposo ou do símbolo da terceira pessoa da Trindade. São Joaquim pode assistir às cenas de educação de sua filha. Quando no segundo plano, sua posição tem uma dimensão simbóli$\mathrm{ca}$, revelando uma figura secundária, às vezes isolada. A pomba pode ser representada sobre o espaldar do trono de Sant'Anna indicando, provavelmente, que a Escritura que ela contempla foi inspirada pelo Espírito Santo.

O tipo iconográfico de Sant’Anna Guia, no qual a mãe anda segurando sua filha pela mão, é menos comum. Freqüentemente ela indica o caminho à sua filha com a outra mão. Um livro pode ser representado nas mãos daquela que guia ou nas de quem segue. Assim sendo, mesmo quando mãe e filha caminham, o livro indica que é a educação de Maria que está em causa.

\section{A Santa do Livro}

"Achei que tratar da educação que deveriam ter as meninas nobres e fidalgas merecia maior atenção porque [...] vem a ser os primeiros mestres de seus filhos, irmãos e marido."

A.N.R. Sanches $(† 1782)^{26}$

O livro indica que os dois tipos iconográficos convergem para o mesmo significado fundamental. Tudo leva a crer que este significado foi responsável pela difusão intensa desta iconografia de Sant'Anna como educadora em Minas. No mundo lusitano, o culto da imagem de Sant'Anna Mestra era estimulado através de indulgências prometidas aos que orassem diante das imagens representadas em gravuras. Enquanto a difusão de estampas na colônia não for bem estudada, outras razões deverão explicar a importância destas imagens nessa sociedade onde poucos saberiam ler as promessas em gravuras. 
O que Sant'Anna ensinava a sua filha? O conteúdo do livro aberto de Sant'Anna Mestra é raramente indicado em esculturas e gravuras (por exemplo: "Salmo 24" e "Deus"). No entanto, há gravuras portuguesas que revelam o sentido do ensinamento, por apresentarem inscrições na parte inferior da estampa ("Psal. 118" e "Prov. 4"). Nas obras do século XVIII, a religião e a virtude compunham a essência da educação da Virgem, e estes valores davam sentido às imagens de Sant'Anna Mestra, norteando os devotos que as contemplavam.

Eduardo Hoornaert associa Sant'Anna Mestra à figura da matrona branca dos engenhos, "que passou a ser considerada guardiā e transmissora da religião". Para o autor, "Sant'Anna é o símbolo da Casa-Grande ensinando o catecismo ao pessoal da senzala". ${ }^{27}$ Como ele não indica fonte histórica alguma para corroborar esta afirmação, privilegiamos outras pesquisas.

Os estudos recentes de Leila Algranti explicam que a educação de meninas era realizada sobretudo em casa, pela mãe. ${ }^{28}$ Os conventos e recolhimentos preparavam as moças para o casamento e velavam por sua honra. Em Portugal, a primeira escola para moças foi fundada em 1782, em um convento; no Brasil, foi necessário esperar até o século XIX.

A profunda distinção entre a educação de moças e a de rapazes era fundada nos papéis que a sociedade esperava de cada um. Em geral, estas deveriam aprender a ler, a escrever, ${ }^{29}$ a fazer as quatro operaçōes aritméticas e, em particular, a costurar e bordar. $\mathrm{O}$ aprendizado da religião e da conduta virtuosa valia mais do que os conhecimentos intelectuais.

O Estado português visava não apenas povoar a colônia, mas ainda transformar mulheres em mães devotas e educadoras. Vários autores leigos ressaltaram a importância das mães na educação das filhas, inclusive especialistas portugueses no século das luzes. Assim como Sant'Anna Mestra era representada com Maria e com seu esposo, considerava-se que o papel das mulheres não se limitava aos filhos, abrangendo deste modo toda a família, como ressaltou A. N. R. Sanches.

O vínculo entre a devoção a Sant'Anna e a educação de meninas é explícito no discurso de Gabriel Malagrida (†1761), um italiano que veio ao Brasil em 1721. Este jesuíta pediu permissão ao rei para fundar institui- 
ções para educar "a mocidade com os bons costumes, educação e doutrina, de que tanto se necessitava aquele Estado". ${ }^{30}$ Dada a sua preocupação com a conversão de mulheres imodestas, Sant'Anna teria fundado uma casa de recuperação feminina em Jerusalém. ${ }^{31}$ Maria teria feito seu "voto de virgindade” durante a gestação no ventre de Sant'Anna, que confirmou-o.

Qual é o significado destas imagens da santa do livro? O papel da mãe educadora nas Minas Gerais elucida o significado sociocultural desta iconografia tão difundida. A mãe branca - a mais rara de todas na colônia - era quem preservava a pureza étnica e racial dos filhos de homens portugueses. Anna era um modelo para as mães; a Virgem inspirava as filhas a aprender as virtudes do catolicismo e a preservar a "flor celeste da virgindade" - valorizada por todos os jesuítas estudados. ${ }^{32}$

No Brasil como na Europa, a Igreja tinha razão para propagar a iconografia de Anna como a santa do livro, pois

com o espírito da Contra-Reforma e a convicção de que a mulher desempenha papel importante na educação dos filhos, chega o grande impulso dado à educação feminina, na tentativa de educar os fiéis para fazerem frente às heresias. ${ }^{33}$

A importância da mãe como educadora foi particularmente pertinente nas Minas Gerais, onde a família era freqüentemente matrifocal e não patriarcal. ${ }^{34}$ Este é o consenso dos historiadores sobre a sociedade de Minas, na qual a mobilidade geográfica dos mineradores privava muitos lares da presença de um pai. A propagação da iconografia de Anna com o livro parece ser intimamente vinculada à valorização da mãe como chefe de família e educadora.

Sant'Anna é uma figura de devoção com atribuições diversas, mesmo quando representada em um universo restrito a três tipos iconográficos. Gloriosa Matriarca, raiz da genealogia messiânica, protetora das viúvas, padroeira dos mineradores e moedeiros, cura dos enfermos, guia e mestra - seus papéis maternais são generosos e polivalentes.

A iconografia da Contra-Reforma revela que a forma mais significativa de uma mãe ser santa foi sendo mestra e guia. A santa do livro é onipresente no catolicismo setecentista das Minas. Mais do que um instumento do saber, o livro é um canal de comunicação, destinado a Maria e aberto também ao fiel que contempla a imagem. 
244 - Tороі

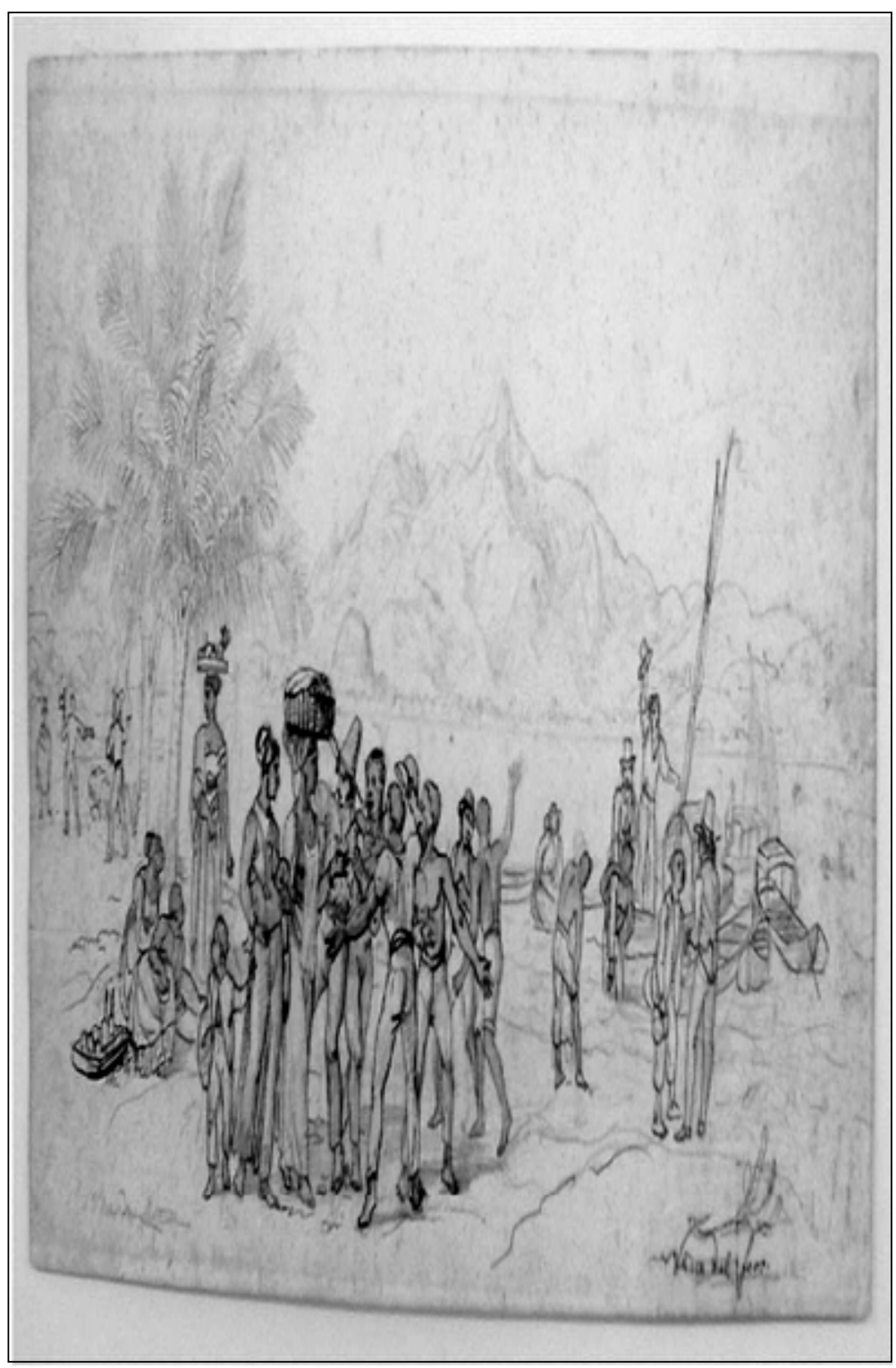


Mãe, mestre e guia: uma análise da iconografia de Sant'Anna 245

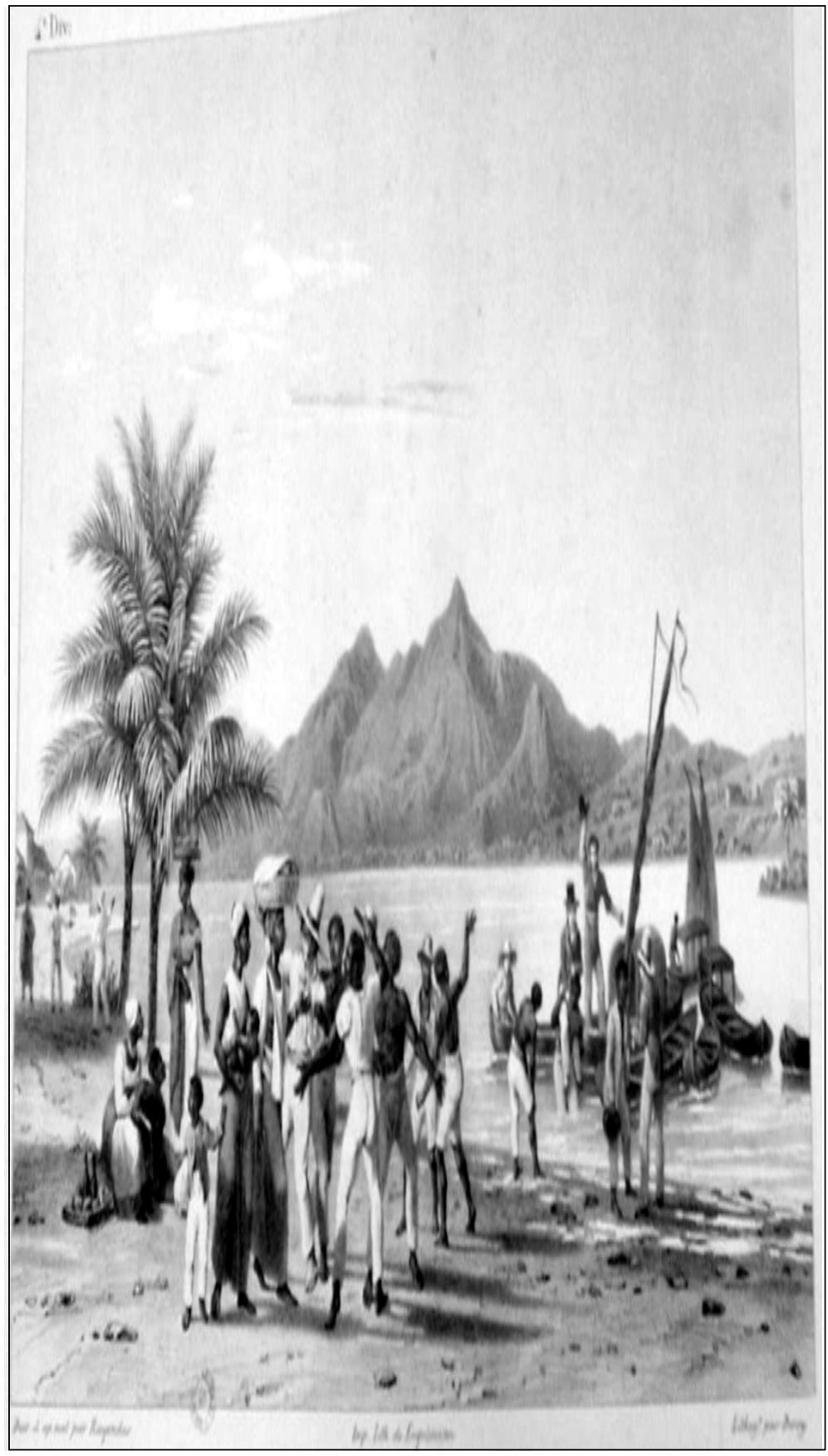




\section{Notas}

${ }^{1} \mathrm{Na}$ Igreja Grega, a celebração ainda é chamada de "Concepção de Anna”. Na Igreja Latina, é conhecida como "Concepção de Maria". Esta festa do dia 8 de dezembro (nove meses antes da festa do nascimento de Maria) não deve ser confundida com a celebração litúrgica de Sant'Anna e São Joaquim, instituída no dia 26 de julho desde 1584, por iniciativa de Gregório XIII. Um aprofundamento da maior parte dos temas tratados neste trabalho pode ser encontrado na Tese de Doutorado de Maria Beatriz de Mello e Souza, Les images de l'Immaculée Conception dans le monde luso-brésilien: leur culte et leur signification (XVIe —XVIIIe siècles). Université de Paris I — Panthéon Sorbonne, 1996. 3 vols. A tese inclui análises de diversas representações literárias e artísticas de Sant'Anna, com ilustrações das obras de arte.

${ }^{2}$ Ver Évangiles Apocryphes, apresentação de France Quéré (Paris, Seuil, 1983), pp. 69-72. ${ }^{3}$ Anchieta, José de. Poema da Bem-Aventurada Virgem Maria, Mãe de Deus. São Paulo: Loyola, 1988. 2 vols. versos 513-514 e 517-518. Trata-se de uma edição bilíngüe, traduzida de De Beata Virgine Dei Matre Maria, com 5.785 versos.

${ }^{4}$ Sermão da gloriosa Santa Anna, Mãy da Mãy de Deos, Pregado (...), em 26 de julho, anno de 1739 . In Sermóes, Lisboa: Miguel Manescal da Costa, 1743. Vol. 1, p. 314.

${ }^{5}$ De acordo com E. Gombrich, “allegory' means literally 'saying something else”. Cf. Gombrich, E. Symbolic images: Studies in the art of the Renaissance. Oxford: Phaidon, 1985. p.19. A respeito da discussão historiográfica sobre a distinção entre alegoria e símbolo, ver pp. 183-187.

${ }^{6}$ No disco Gerais (1975), Milton Nascimento interpreta a canção popular Cálix Bento, que apresenta a mesma idéia da iconografia: "De Jessé nasceu a vara, / e da vara nasceu a flor, / e da flor nasceu Maria, / de Maria, o Salvador".

${ }^{7}$ In Missae Propriae Sanctorum Hispanorum... Venitiis: Typ. BalleoniAnna, 1760. p. 25.

${ }^{8}$ Para Jorge de Carvalho, O.S.B., assim como Cristo é a "imagem” de Deus, Maria é "uma cópia” de Sant'Anna. Uma é “o retrato” da outra. Cf. Sermão... em dia de Santa Anna, no Mosteiro de Santa Anna, professando Soror Anna Maria... Lisboa: Officina de Lourenço de Anveres, 1646 e Coimbra: Thome Carvalho, 1672. p. 5-6.

${ }^{9}$ Um exemplo português da devoção medieval a Sant'Anna que enfatiza esta linhagem genealógica encontra-se em A vida e linhagem de Sancta Anna, Madre de Nossa Senhora e Começa aqui a vida de Sancta Anne e Sam Joachim, seu marido, até que Nosa Senhora nasceo, textos reproduzidos em Lucas, Maria Clara de Almeida. Ho Flos Sanctorum em Lingoage: os Santos Extravagantes. Lisboa: Instituto Nacional de Investigação Científica, 1988. pp.253-265.

${ }^{10}$ Voltaremos a este tópico na terceira parte do texto.

${ }^{11}$ Cf. Sermão da Senhora Santa Anna... In Sermões. 1798. Tomo I, pp. 228-256. O sermão é baseado na parábola de Mateus, 7: a árvore que é conhecida por seus frutos. 
12 Bayão, José Pereira (†1743). Vida, prerrogativas e excelências da inclita matrona Santa Anna, em que se prova com eficácia não casar mais que uma só vez, traduzida e acrescentada com muitos milagres dela e do senhor São Joaquim, seu único esposo.

${ }^{13}$ Azevedo, Sebastiāo. Céu místico à gloriosissima senhora Santa Anna. Lisboa, 1725; Santanna, José Pereira de. Noticia mystica, representacion metrica y verdadera historia de los abuelos de Maria e bisabuelos de Christo (...) offerecida a la gran madre de la Virgen inclita, y soberAnna abuela de Jesus S. Anna (...). Lisboa: Impressão da Música, 1730; J. P. de Santanna (Rio de Janeiro, 1696 - Portugal, 1759) era cronista dos carmelitas, Doutor em Teologia da Universidade de Coimbra, visitador das ordens militares e do Patriarcado, qualificador da Inquisição e confessor das Infantas de Portugal. Escreveu ainda Medianeira da vida eterna, Maria Santissima, Mãy de Deus (...) Parte II. Comprehende (...) devoçoens em louvor, não só da Virgem Senhora, mas tambem da Senhora Santa Anna, S. Joseph, e outros grandes santos da Sagrada Familia (...) Offerecida à Mesma Soberana Imperatriz da Glória (...) Lisboa: Antonio Pedroso Galrão, 1747.

${ }^{14}$ Natividade, Francisco da. Novena de Senhora Sant'Anna com o seu Ofício. 1708; Engrácia, Antonio de Santa. Novena de Sant'Anna, Avó de Cristo. 1720; Belém, Jerônimo de. Excelência da mulher forte ou novena de Sant'Anna. 1733. Natividade era carmelita e Santa Engrácia, franciscano; J. de Belém nasceu no Brasil. E, posteriormente, Silva, Antonio José da. Novena da gloriosa Sant’Anna, Mãe de Deus, Avó de Cristo. Lisboa, 1770; Melo, Inácio de. Tres hymnos latinos a Nossa Senhora e hum a sua Mãy a Senhora Santa Anna (s.l., s.n., s.d.); nenhum exemplar deste livro é conhecido em bibliotecas portuguesas.

${ }^{15}$ Cf. Carvalho, J. de. Op. cit. pp. 5-6 e 20.

${ }^{16}$ Soares, João Alvares. Sermão da gloriosa S. Anna, Mãy de Maria SS. Senhora Nossa, na festa que lhe consagrão os Moedeiros na Catedral da Cidade da Bahia. Lisboa: Officina Augustinianna, 1733. pp.1-31. O autor, padre secular, estudou no colégio de jesuítas da Bahia, onde nasceu em 1676. Santa Anna, Antonio de, Frei. Sermão II da gloriosa Senhora Santa Anna, Mãy da Mãy de Deos, e Avó de Jesu Christo, que se havia de pregar na Santa Sé Metropolitana de Lisboa Oriental na festa, que anualmente lhe fazem os seus devotos da Casa de Moeda, anno 1730. In Sermões varios. Lisboa: 1738. pp. 460-483.

${ }^{17}$ Cf. Mott, Luiz. Rosa Egipcíaca. Uma santa africana no Brasil. Rio de Janeiro: Bertrand, 1993., p.122 e 496-497, grifo nosso.

${ }^{18}$ Ela recebe como revelação uma canção que invoca Anna, Joaquim e Maria. Em 1754, Rosa vê os corações que passam a ser objetos de uma devoção afetuosa: ela acrescenta os de Anna e Joaquim aos coraçōes de Jesus, Maria e José. Idem. pp.286-287, 299-300 e 313-332.

${ }^{19}$ Entre as 322 irmandades em Minas, onze adotaram Anna como padroeira. Cf. Boschi, Caio. Os leigos e o poder: irmandades leigas e politica colonizadora em Minas Gerais. São Paulo: Ática, 1986. pp.187-188, 190 e 198-199.

${ }^{20}$ Ver, por exemplo, Bayão, José Pereira. Op.cit.

${ }^{21}$ Sobre Anna e Joaquim como casal modelo, ver Holwecke, Frederick. Saint Anne. In The Catholic Encyclopedia. New York, 1907. Vol.1. Sobre a instabilidade familiar em Minas, 
ver Souza, Laura de Mello e. Desclassificados do ouro. A pobreza mineira no século XVIII. Rio de Janeiro: Graal, 1982 e a tese de doutorado de Renato Pinto Venâncio defendida na Universidade de Paris IV-Sorbonne em 1993. Entre 1719 e 1723, 90\% das crianças nascidas em Minas Gerais eram ilegítimas: este índice revela o quanto esta sociedade carecia da formação de famílias estáveis na perspectiva da Igreja.

22 Por exemplo, o professor M. O., 30 anos foi denunciado em Pernambuco, em 1594, por afirmar que "Sant'Anna primeiro que parisse a Virgem Senhora parira outras filhas". Cf. Mott, Luiz. Maria, virgem ou não? Quatro séculos de contestação no Brasil. Trabalho apresentado na XV Reunião da Associação Brasileira de Antropologia. Curitiba, 1986. p. 10 .

${ }^{23}$ Cf. Mott, Luiz. Rosa Egipcíaca. Uma santa africana no Brasil. Rio de Janeiro: Bertrand, 1993. p. 508.

${ }^{24}$ Idem. p. 30.

${ }^{25}$ Para um estudo sobre a imagem medieval de Sant'Anna Mestra, ver Sheingorn, Pamela. The wise mother: the image of Saint Anne teaching the Virgin Mary. Gesta, vol. 32, n. 1, pp.69-80, 1993. Sobre a mesma imagem na época da Contra-Reforma, ver Ruiz-Calvez, Estrella. Religion de la mère, religion des mères. Sainte Anne éducatrice: les images de la mère selon l'iconographie de Sainte Anne. XVe-XVII siècle. In Delumeau, Jean (Dir.). La religion de ma mère. Les femmes et la transmission de la foi. Paris: Cerf, 1992. pp.123155.

${ }^{26}$ Apud Algranti, L. M. Honradas e devotas: mulheres da Colônia: condição feminina nos conventos e recolhimentos do Sudeste do Brasil, 1750-1822. Rio de Janeiro; Brasília: José Olympio; EdUnB, 1993. p. 243.

${ }^{27}$ Cf. História da Igreja no Brasil. Primeira época. Petrópolis: Vozes, 1979. pp. 370-371.

${ }^{28}$ Cf. Educação de meninas: a clausura provisória. Idem. pp.239-261. Entre as instituições estudadas, a de Macaúbas, em Minas, foi a principal dedicada à educação de moças (cf. pp.23-25 e 253-255). Ver também Priore, Mary del. Ao sul do corpo: condição feminina, maternidades e mentalidades no Brasil colônia. Rio de Janeiro; Brasília: José Olympio; EdUnB, 1993. pp. 309-320.

${ }^{29}$ A porcentagem de mulheres livres que sabiam assinar o nome era extremamente baixa. Chegava a 2,2\% no Rio de Janeiro de 1808-26 (e 40,33\% dos homens livres). Cf. Algranti, L. M. Op.cit. p. 251.

${ }^{30}$ Idem, p. 76.

${ }^{31}$ Cf. Heróica e admirável vida da gloriosa Sant'Anna, Mãe de Maria Santíssima, ditada pela mesma Santa com assistência, aprovação e concurso da mesma Soberanissima Senhora e de seu Santíssimo Filho. 120 folhas, apud Mott, L. Op. cit. p. 503.

${ }^{32} \mathrm{O}$ jesuíta Alexandre de Gusmão (1629-1724) assinalou a importância da educação de moças no Brasil, recomendando que se tornassem devotas da Virgem para este fim. Cf. Gusmão, Alexandre de. Arte de crear bem os filhos em idade de puerícia. Lisboa, 1685. p. 287. Ver o capítulo 25, pp.377-87, "Do especial cuidado que se devem na creaçam das meninas". 
33 Algranti, L. M. Op.cit., p. 241.

${ }^{34}$ Sobre famílias matrifocais, ver Figueredo, Luciano. $O$ avesso da memória: cotidiano e trabalho da mulher em Minas Gerais no século XVIII. Rio de Janeiro; Brasília: José Olympio; EdUnB, 1993 e Souza, Laura de Mello e. Op. cit. Para Michael Carroll, a estrutura familiar que ele chama "father ineffective family" é muito importante para explicar o culto mariano, sobretudo na Itália e na Espanha. Carroll, Michael. The cult of the Virgin Mary: psychological origins. Princeton: Princeton University Press, 1986. E o culto mariano é o fundamento da devoção a Sant'Anna. Para uma crítica historiográfica sobre a família patriarcal na colônia, ver Vainfas, Ronaldo. Trópico dos pecados: moral, sexualidade e Inquisição no Brasil colonial. Rio de Janeiro: Campus, 1989. Capítulo 4: "Patriarcalismo e Misoginia”, pp.107-142.

\section{Abstract}

The Virgin Mary and her mother, Anne, were the most popular female saints in Brazil throughout the seventeenth and eighteenth centuries. The devotion to this "the glorious matriarch"is, indeed, a reflection of the marian cult. Anne even came to be associated with some of the virtues of the Mother of Christ. Three types of artistic representations highlight this association by portraying Anne as mother, guide and, moreover, mistress. This paper proposes an interpretation of these iconographic types in light of both catholic thought and the social context of Minas Gerais. This region harbored the greatest art center of Portuguese America in the XVIIIth century and sculptures of Saint Anne were prominent in most parishes and chapels there. They became cult images for individuals and various groups. The aim of this research is to understand the meaning of these images that are not rooted in any scriptural passage; they are, rather, a cultural portrayal of the roles assigned to motherhood.

\section{Resumo}

A Virgem Maria e sua mãe, Anna, foram as santas mais populares no Brasil ao longo dos séculos XVII e XVIII. A devoção a esta "gloriosa matriarca" é, com efeito, um reflexo do culto mariano. Anna veio até a ser associada com algumas virtudes da Mãe de Cristo. Três tipos de representação artística ilustram esta associação ao retratarem Anna como mãe, guia, e, sobretudo, mestra. Este trabalho propõe uma interpretação destes tipos iconográficos à luz do pensamento católico e do contexto social de Minas Gerais. Esta região testemunhou a emergência do mais importante centro artístico da América Portuguesa no século XVIII; esculturas de Santa Anna ocupavam um lugar 
de destaque em paróquias e capelas mineiras. Tornaram-se imagens de culto para individuos e grupos diversos. O objetivo desta pesquisa é compreender o significado destas imagens que não estão enraizadas em passagem alguma das Escrituras; elas constituem, ao contrário, um retrato cultural dos papéis atribuidos à maternidade. 